\title{
Crystal Structure Refinement of 1,4,5,8-Tetrabromonaphthalene: A Twisted Chiral Naphthalene Induced by Steric Repulsion
}

\author{
Md Awlad Hossain, *** Kazunori Hirabayashi,* Tohru Nishinaga,* Toshio Shimizu,* and \\ Ken-ichi SugIURA *广ं
}

*Department of Chemistry, Graduate School of Science, Tokyo Metropolitan University, 1-1 Minami-Osawa, Hachi-Oji, Tokyo 192-0397, Japan

**Department of Chemistry, Jahangirnagar University, Savar, Dhaka-1342, Bangladesh

\begin{abstract}
The molecular structure of sterically crowded 1,4,5,8-tetrabromonaphthalene 1 was refined. The compound crystallized in a monoclinic system and was characterized as follows: $P 2_{1} / c, a=9.470(3), b=15.530(4), c=7.340(2) \AA, \beta=92.147(9)^{\circ}$, $Z=4, V=1078.7(5) \AA^{3}$. The crystal structure was solved by direct methods and refined by full-matrix least-squares on $F^{2}$ to final values of $R 1=0.0332$ and $w R 2=0.0572$. Because of the steric repulsion between the peri-bromines, 1 takes a twisted structure having a $D_{2}$ point group, i.e., a chiral structure. Symmetry operation of this space group generates the corresponding enantiomer in the crystal. In marked contrast to the noticeably short intramolecular $\mathrm{Br}-\mathrm{Br}$ contact of $3.209 \AA$ (average), there is no short Br-Br contact intermolecularly.
\end{abstract}

(Received May 25, 2020; Accepted June 9, 2020; Published on web September 10, 2020)

The peri-positions of an aromatic hydrocarbon, such as the 1and 8-positions of naphthalene, are unique because of their closeness. The distance of hydrogens at the peri-positions of naphthalene is $2.446 \AA$, ${ }^{1}$ which is comparable to the sum of the van der Waals (vdW) radii of two hydrogen atoms $2.40 \AA .^{2}$ Therefore, all of the elements and/or groups introduced on these positions induce short atomic contact that is smaller than the sum of vdW radii of two hydrogen atoms. Such peridisubstituted compounds as 1,8-disubstituted naphthalene are important models of this overcrowded space. Two representative examples are known. One is a non-covalent interaction, such as the short atomic contacts of chalcogens for 1,8-dichalcogenonaphthalene in the context of research on two-center fourelectron $\sigma$ - and $\pi$-bonds. ${ }^{3}$ Another example is a incorporation of a proton in 1,8-bis(dimethylamino)naphthalene, which is known as proton sponge. ${ }^{4}$ Such halogen derivatives as 1,8-dihalogenonaphthalenes have also attracted much attention. The molecules have been used as precursors for the abovementioned chemistry, and their distorted structures are interesting for elucidating the relationship between the electronic structure and the distortion of the molecule. ${ }^{5}$ Among them, we focused on 1,4,5,8-tetrabromonaphthalene 1 (Fig. 1) because of its simple preparation and wide applications. Its single-crystal diffraction study was carried out in $1968 .{ }^{6}$ Unfortunately, the resolution of that experiment is not sufficient for contemporary science. Here we report the refinement of the molecular structure of $\mathbf{1}$ and discuss the twisted distorted structure.

The synthesis of the title compound $\mathbf{1}$ was performed according to a revised method reported in 2015. ${ }^{7}$ A single crystal suitable for a diffraction study was harvested from acetic acid. ${ }^{6}$ X-ray diffraction data for the crystal were collected using a Rigaku XtaLAB P200 diffractometer with graphite monochromated Mo- $K \alpha$ radiation. The crystal information is

$\dagger$ To whom correspondence should be addressed.

E-mail: sugiura@ porphyrin.jp given in Table 1 and the details are described in Supporting Information \#1, SM\#1. Theoretical studies carried out with a Gaussian program (Ver. 16, Revision A.03) and the details are shown in SM\#2.

The title molecule should have several conformational isomers that originate from the atomic repulsion manner of peribromines, such as $\mathbf{1 a}$ (point group: $\left.D_{2} h\right), \mathbf{1 b}\left(C_{2}\right), \mathbf{1 c}\left(D_{2}\right)$, and 1d $\left(C_{2} h\right)$ shown in Fig. 1. The molecular structure obtained by a diffraction study is shown in Fig. 2. The most significant structural feature of $\mathbf{1}$ would be the extremely short $\mathrm{Br}-\mathrm{Br}$ contacts, 3.2129(8) $\AA$ for Br1-Br4 and 3.2056(8) $\AA$ for $\mathrm{Br} 2-\mathrm{Br} 3$, which are much shorter than the sum of the vdW radii of two<smiles></smiles>

1a<smiles>O=C(O)C1(Br)C(Br)=C(Br)c2c(Br)ccc(Br)c21</smiles>

$1 c$<smiles>Brc1ccc(Br)c2c(Br)ccc(Br)c12</smiles>

$1 \mathrm{~b}$<smiles>Brc1ccc(Br)c2c(Br)ccc(Br)c12</smiles>

Fig. 1 Four plausible stereoisomers

Fig. 1 Four plausible stereoisomers
naphthalene along with their point groups.

of 1,4,5,8-tetrabromo-

\footnotetext{
$$
\text { (1) }
$$
}


Table 1 Crystal and experimental data
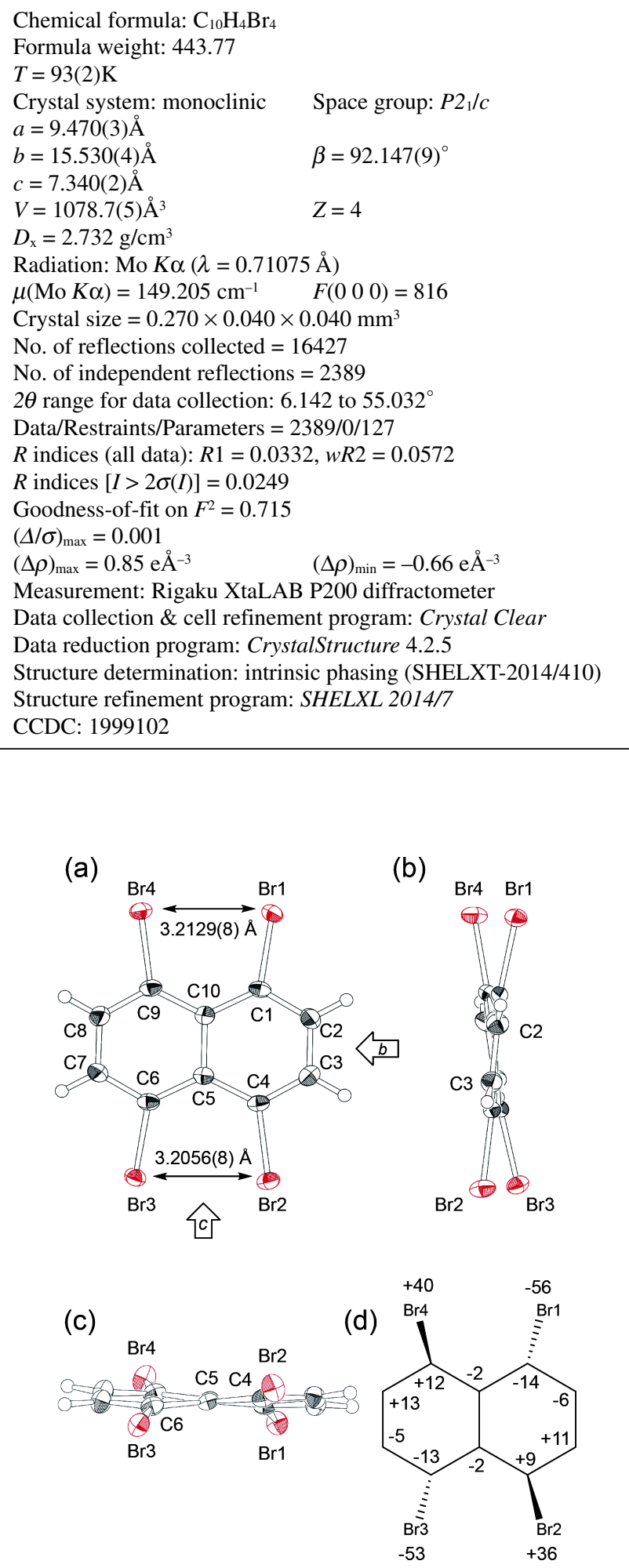

Fig. 2 ORTEP drawing of $\mathbf{1}$ showing the thermal ellipsoid at $50 \%$ probability. (a) Top view, (b) side view from white arrow-b shown in (a), (c) bottom view from white arrow-c shown in (a), and (d) out-ofplane displacements (in units of $0.01 \AA$ ) of each atom from the leastsquares naphthalene mean plane defined by ten carbon atoms.

bromines, $3.70 \AA^{2} .^{2}$ These contacts induce a large steric repulsion, and the atoms are located above and below the naphthalene mean plane. The deviations of the individual atoms
Table 2 Bond distances $(\AA)$ and selected angles $\left(^{\circ}\right)$ of $\mathbf{1}$ (Mean bond distances for bond $\alpha,-\beta,-\gamma,-\delta$, and $-\varepsilon$ and mean angles for $\psi$ and $\omega$ are also shown, assuming 1 takes perfect $D_{2}$ symmetry (the definitions for $\alpha, \beta, \gamma, \delta, \varepsilon, \psi$, and $\omega$ are shown in Fig. 1c))

\begin{tabular}{|c|c|c|c|}
\hline \multicolumn{4}{|l|}{$\alpha=1.912(3)$} \\
\hline $\mathrm{Br} 1-\mathrm{C} 1$ & $1.909(3)$ & $\mathrm{Br} 2-\mathrm{C} 4$ & $1.918(3)$ \\
\hline Br3-C6 & $1.908(3)$ & Br4-C9 & $1.914(3)$ \\
\hline \multicolumn{4}{|c|}{$\beta=1.433(4)(\text { ref. } 1.4168(1))^{\mathrm{a}}$} \\
\hline $\mathrm{C} 1-\mathrm{C} 10$ & $1.430(4)$ & $\mathrm{C} 4-\mathrm{C} 5$ & $1.440(4)$ \\
\hline C5-C6 & $1.433(4)$ & C9-C10 & $1.430(4)$ \\
\hline \multicolumn{4}{|c|}{$\gamma=1.370(5)(\text { ref. } 1.3735(1))^{\mathrm{a}}$} \\
\hline $\mathrm{C} 1-\mathrm{C} 2$ & $1.373(5)$ & $\mathrm{C} 3-\mathrm{C} 4$ & $1.360(4)$ \\
\hline C6-C7 & $1.377(4)$ & C8-C9 & $1.369(4)$ \\
\hline \multicolumn{4}{|c|}{$\delta=1.394(5)($ ref. $1.4162(1))$ a } \\
\hline C2-C3 & $1.396(5)$ & C7-C8 & $1.391(4)$ \\
\hline \multicolumn{4}{|c|}{$\varepsilon=1.470(4)(\text { ref. } 1.4216(1))^{\mathrm{a}}$} \\
\hline C5-C10 & $1.470(4)$ & & \\
\hline \multicolumn{4}{|l|}{$\psi=112.3(2)$} \\
\hline$\angle \mathrm{Br} 1-\mathrm{C} 1-\mathrm{C} 2$ & $112.3(2)$ & $\angle \mathrm{Br} 2-\mathrm{C} 4-\mathrm{C} 3$ & $112.4(2)$ \\
\hline$\angle \mathrm{Br} 3-\mathrm{C} 6-\mathrm{C} 7$ & $112.0(2)$ & $\angle \mathrm{Br} 4-\mathrm{C} 9-\mathrm{C} 8$ & $112.5(2)$ \\
\hline \multicolumn{4}{|l|}{$\omega=125.5(2)$} \\
\hline$\angle \mathrm{Br} 1-\mathrm{C} 1-\mathrm{C} 10$ & $125.4(2)$ & $\angle \mathrm{Br} 2-\mathrm{C} 4-\mathrm{C} 5$ & $125.0(2)$ \\
\hline$\angle \mathrm{Br} 3-\mathrm{C} 6-\mathrm{C} 7$ & $126.0(2)$ & $\angle \mathrm{Br} 4-\mathrm{C} 9-\mathrm{C} 10$ & $125.5(2)$ \\
\hline
\end{tabular}

a. From Ref. 1.

from the least-squares naphthalene mean plane, defined by ten carbon atoms, are given in Fig. 2(d). The root-mean-square outof-plane displacement, $\Delta$, of the naphthalenic ten atoms from the least-squares plane is $0.096 \AA .^{8}$ The corresponding chloride, 1,4,5,8-tetrachloronaphthalene, also takes a similar conformation, as expected, and the $\Delta$ value is smaller, $0.036 \AA$. ${ }^{9}$ This twisted form is chiral, as seen in the structures of 1,8-bis(1-adamantyl)naphthalene derivatives, i.e., equatorenes. ${ }^{10}$ The crystal of 1 belongs to the $P 2_{1} / c$ space group; therefore, the corresponding enantiomer is generated by a symmetry operation of this space group (vide infra).

It is known that naphthalene exhibits a unique bond alternation. ${ }^{1}$ The mean bond distances for bond- $\beta,-\gamma,-\delta$, and $-\varepsilon$ of $\mathbf{1}$ (for definitions, see Fig. 1) are 1.433(4), 1.370(5), 1.394(5), and $1.470(4) \AA$, respectively (Table 2 ). These distances are significantly longer (for bond- $\beta$ and $-\varepsilon$ ) and shorter (for bond $\delta$ ) than the corresponding bonds of naphthalene, ${ }^{1}$ considering the standard deviations $3 \sigma$ of the experiments. Theoretical calculations (vide infra) for $\mathbf{1 c}$ and naphthalene also support this tendency (see SM\#2).

To consider the details of the conformational isomerism of $\mathbf{1}$, theoretical studies were carried out. The structural optimizations for 1a-1d were carried out under a vacuum condition, and it was found that $\mathbf{1 c}$ is the most stable one. The energies of 1a, $\mathbf{1 b}$, and $\mathbf{1 d}$ are $1.2,0.8$, and $1.0 \mathrm{kcal} \mathrm{mol}^{-1}$ higher than that of 1c. Normal coordination analyses were also carried out for 1a-1d; 1a has two $\left(i=-24.18\right.$ and $\left.-19.85 \mathrm{~cm}^{-1}\right)$ imaginary frequencies, whereas $\mathbf{1 b}$ and $\mathbf{1 d}$ have one $\left(i=-15.36 \mathrm{~cm}^{-1}\right.$ and $i$ $=-12.44 \mathrm{~cm}^{-1}$, respectively) imaginary frequency. Based on these results, we conclude that $\mathbf{1 c}$ racemizes at room temperature quickly through $\mathbf{1 b}$ as the transition state.

The packing motif of 1c is shown in Fig. 3. As mentioned above, the observed 1c is chiral and the stereochemistry shown in Fig. 2 is $(M, M)$ using helicene terminology. The corresponding enantiomer, $(P, P)$ isomer, is generated by an inversion operation. In the $b$-axis direction, $(M, M)$ and $(P, P)$ isomers are stacked alternately to produce a one-dimensional (1D) column. The interplanar interactions are nonuniform, i.e., the interplanar distances are 3.654 and $3.667 \AA$ (Fig. 3(b)). It is worth 
(a)

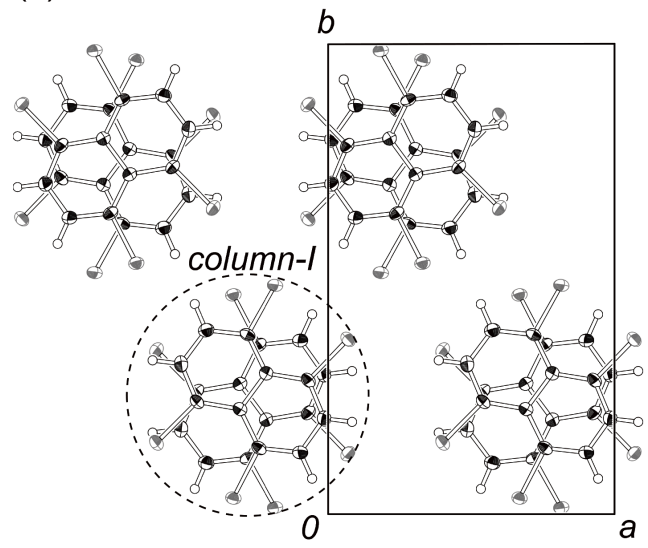

(b)

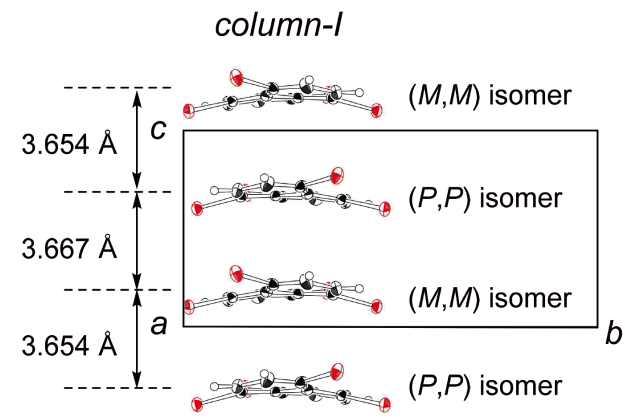

(c)

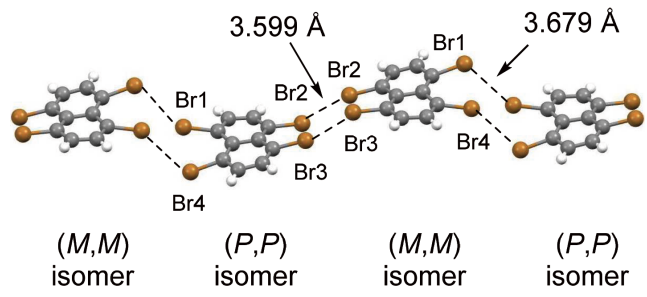

Fig. 3 Packing and intermolecular interaction diagrams of $\mathbf{1}$. (a) Packing diagram shown along the $c$-axis. (b) Nonuniform 1D column produced by $(P, P)$ - and $(M, M)$-isomers. The interplanar distances between the least-squares naphthalene mean planes are 3.667 and $3.654 \AA$. (c) $1 \mathrm{D}$ ladder sheet formed by $\mathrm{Br}-\mathrm{Br}$ interactions.

emphasizing that there is no significant intermolecular short $\mathrm{Br}-\mathrm{Br}$ contact that is smaller than the sum of the vdW radii of two bromines $(3.70 \AA)$. The shortest distance was found between the 1D columns, 3.5992(8) $\AA$, which produced another 1D ladder sheet structure in the (1.1.0) and (-1.-1.0) directions (Fig. 3(c)). This aggregation motif was found in a STM study. ${ }^{7}$ The lack of a short intermolecular atomic interaction might be the reason for the relatively low melting point of $1,145^{\circ} \mathrm{C} .^{7}$

The molecular structure of $\mathbf{1}$ was characterized. The characteristic features of this molecule could contribute to advanced materials chemistry, including surface science.

\section{Acknowledgements}

This work was supported in part by the Cooperative Research Program of "Network Joint Research Center for Materials and Devices: Dynamic Alliance for Open Innovation Bridging Human, Environment and Materials" Grant Number 20201317, and the Priority Research Program sponsored by the Asian Human Resources Fund of Tokyo Metropolitan Government (TMG).

\section{Supporting Information}

This material is available free of charge on the Web at http:// www.jsac.or.jp/xraystruct/.

\section{References}

1. J. Oddershede and S. Larsen, J. Phys. Chem. A, 2004, 108, 1057. In this work, four diffraction studies on naphthalene were performed at various temperatures. We used the structure measured at $100 \mathrm{~K}$; CSD\#:NAPHTA15.

2. A. Bondi, J. Phys. Chem., 1964, 68, 441.

3. S. Hayashi, M. Uegaito, T. Nishide, E. Tanaka, W. Nakanishi, T. Sasamori, N. Tokitoh, and M. Minoura, New J. Chem., 2019, 43, 14224.

4. J.-C. Chambron and M. Meyer, Chem. Soc. Rev., 2009, 38, 1663.

5. M. A. Dobrowolski, M. K. Cyranski, and Z. Wrobel, Phys. Chem. Chem. Phys., 2016, 18, 11813.

6. M. A. Davydova and Y. T. Struchkov, J. Struct. Chem., 1968, 9, 198

7. H. Zhang, H. Lin, K. Sun, L. Chen, Y. Zagranyarski, N. Aghdassi, S. Duhm, Q. Li, D. Zhong, Y. Li, K. Mullen, H. Fuchs, and L. Chi, J. Am. Chem. Soc., 2015, 137, 4022.

8. The root-mean-square out-of-plane displacement $(\Delta)$ is defined as follows:

$\Delta=\sqrt{\sum_{\mathrm{i}=1}^{10} \frac{\delta_{\mathrm{i}}^{2}}{10}}$

where $\delta_{\mathrm{i}}$ is the orthogonal displacement of macrocycle atom $i$ from the mean plane: W. Jentzen, I. Turowska-Tyrk, W. R. Scheidt, and J. A. Shelnutt, Inorg. Chem., 1996, 35, 3559.

9. G. Gafner and F. H. Herbstein, Acta Crystallogr., 1962, 15, 1081. The value was calculated using the coordinates registered on Cambridge Structural Database; \#TCNAPH.

10. K. Yamamoto, N. Oyamada, S. Xia, Y. Kobayashi, M. Yamaguchi, H. Maeda, H. Nishihara, T. Uchimaru, and E. Kwon, J. Am. Chem. Soc., 2013, 135, 16526. 